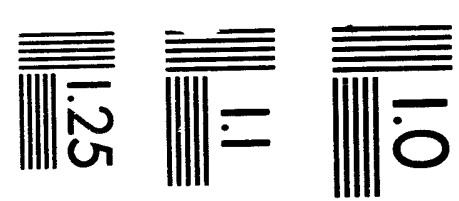

$$
\begin{aligned}
& \overline{\overline{\overline{\bar{n}}}}
\end{aligned}
$$

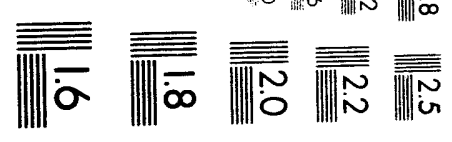



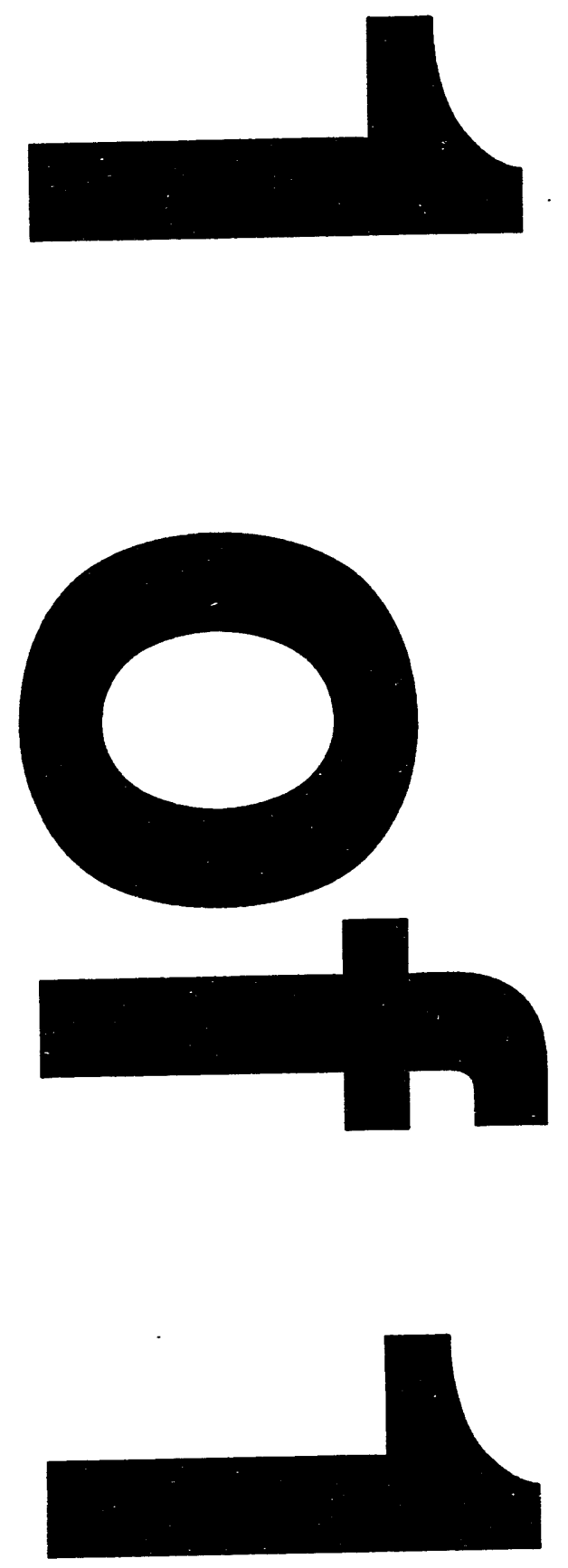


\section{Conf-9310265--1}

LA-UR- 93-4341

LA-UR- $93-4341$ Title:
Author(s):

BINARY-BINARY COLLISIONS INVOLVING MAINSEQUENCE STARS, WHITE DWARFS AND NEUTRON STARS
IN GLOBULAR CLUSTERS

PETER J. T. LEONARD, LOS ALAMOS NATIONAL LAB MELVYN B. DAVIES, CALIFORNIA INSTITUTE OF TECHNOLOGY

Submitted to:

EVOLUTION OF X-RAY BINARIES

\section{MASTR}

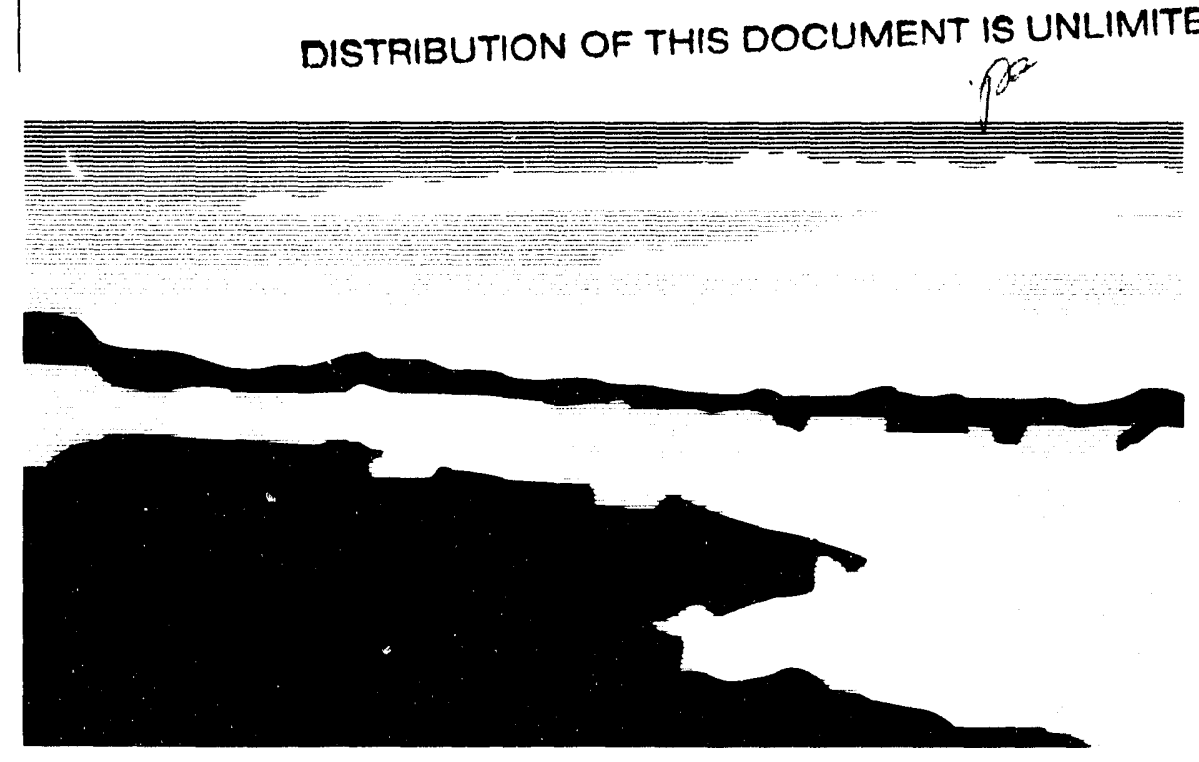

Los Alamos National Laboratory, an aftirmative action/equal opportunity emplóyer, is operated by the University of California tor the U.S. Department of Energy under contract W-7405-ENG-36. By acceptance of this article, the publisher recognizes that the U.S. Government retains a nonexclusive, royalty-free license to publish or reproduce the published form of this contribution, or to allow others to do so, for U.S. Government purposes. The Los Alamos National Laboratory requests that the publisher identify this article as work performed under the auspices of the U.S. Department of Energy. 


\section{DISCLAIMER}

This report was prepared as an account of work sponsored by an agency of the United States Government. Neither the United States Government nor any agency thereof, nor any of their employees, makes any warranty, express or implied, or assumes any legal liability or responsibility for the accuracy, completeness, or usefulness of any information, apparatus, product, or process disclosed, or represents that its use would not infringe privately owned rights. Reference herein to any specific commercial product, process, or service by trade name, trademark, manufacturer, or otherwise does not necessarily constitute or imply its endorsement, recommendation, or favoring by the United States Government or any agency thereof. The views and opinions of authors expressed herein do not necessarily state or reflect those of the United States Government or any agency thereof. 


\title{
BINARY-BINARY COLLISIONS INVOLVING MAIN-SEQUENCE STARS, WHITE DWARFS AND NEUTRON STARS IN GLOBULAR CLUSTERS
}

\author{
Peter J. T. Leonard \\ T-6, MS B288, Los Alamos National Laboratory, Los Alamos, NM 87545 \\ pjtl@eagle.lanl.gov \\ Melvyn B. Davies \\ 130-33, California Institute of Technology, Pasadena, CA 91125 \\ mbd@tapir.caltech.edu
}

\begin{abstract}
We consider collisions between dynamically-evolved primordial binaries consisting of main-sequence stars, white dwarfs and neutron stars in globular clusters. In our four-body binary-binary scattering experiments, we allow stars to "stick" if they pass close enough to each other, which leads to the formation of a wide variety of exotic objects. Most of these objects have binary companions. Also, relatively clean exchange interactions can produce binaries containing neutron stars that eventually receive material from their companions. Such systems will be obscrvable as X-ray binaries.
\end{abstract}

\section{INTRODUCTION}

Collisions between dynamically-evolved primordial binaries consisting of main-sequence stars (MSSs), white dwarfs (WDs) and neutron stars (NSs) must occur in globular clusters, and the purpose of this project is to study such interactions. To reduce the parameter space, we consider only binaries containing at least one MSS. In our scattering experiments, we allow stars to "stick" if they pass close enough to each other. Multiple collisions can take place. The various kinds of stellar mergers that can occur directly or following a common envelope phase and/or the emission of gravitational radiation are 1) MSS-MSS, 2) MSSWD, 3) MSS-NS, 4) WD-WD, 5) WD-NS, and 6) NS-NS. The exotic phenomena that result from such mergers may include blue stragglers, red giants, ThorneZytkow objects, accretion disks around compact objects, spun-up pulsars, ms pulsars formed via AIC, Type Ia supernovae, black holes, and gamma-ray bursts.

\section{THE SCATTERING EXPERIMENTS}

The scattering experiments were carried out using a modified version of the code originally developed by Alexander (1986). The adopted masses are $M_{M S S}=0.7 M_{0}, M_{W D}=0.7 M_{0}$ and $M_{N S}=1.4 M_{\odot}$. The adopted radii are $R_{M S S}=0.7 R_{0}, R_{W D}=0.01 R_{\odot}$ and $R_{N S}=0.0 R_{\odot}$. Stars are allowed to "stick" together if they pass close cnough. The radius of "stickyness" is $R_{\text {stick }}=\Sigma R_{\text {MSS }}$ for MSS-MSS encounters, and $R_{\text {stick }}=2 R_{\text {MSS }}$ for MSSWD and MSS-NS encounters. Two MSSs that merge become a $1.4 M_{\odot}$ MSS with a radius of $1.4 R_{(0)}$. For. WD-WD cncounters, $R_{\text {stick }}=\Sigma R_{W D}$. However, 
direct collisions between WDs are rery rare, since WDs are much more likely to collicle with MSSs first. The semi-major axes and eceentricities of both binaries are $a=50 R_{0}$ and $c=0.6$, respectively. The relative volocity at infinity woll before the interaction begins is $V$ rel, $=10 \mathrm{~km} \mathrm{~s}^{-1}$. The impact paraneter, $b$, is generated from the distribution $d N / d b \propto b$ for $0 \leq b \leq b_{m a x}$. The values of bmar are $36.29 a, 40.46 a$ and $44.24 a$ for collisions involving zero, one and two NSs, respectively. In all cases, bmax corresponds to a pericenter distance of $6 a$ for the relative two-body hyperbolic orbit of the hinary centers of mass, which is extremely unlikely to load to a strong interaction.

\section{THE RESULTS}

The following tables state the number, $n$, of the varions types of mergers that occured in 1000 examples of varions kinds of binary-hinary collisions. The corresponding cross section is $(11 / 1000) \pi l_{\max }^{2}$. The number in brackets is the number of merged stars that have binary companions.

\section{A. (MSS+MSS) (MSS+MSS) Collisions}

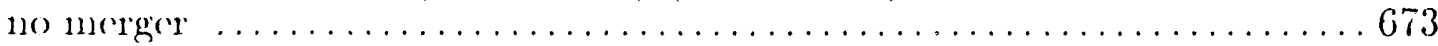

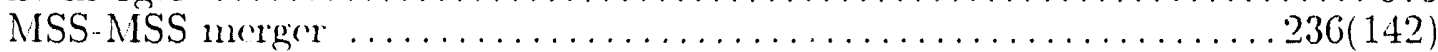

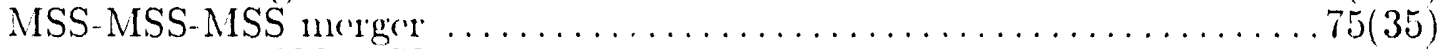

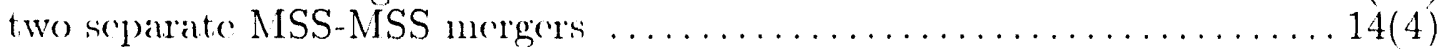

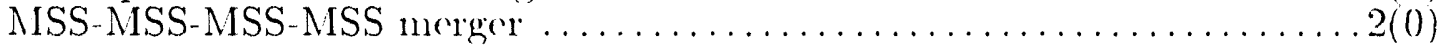

B. (MSS+MSS) (MSS+WD) C'ollisions

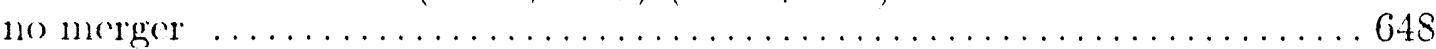

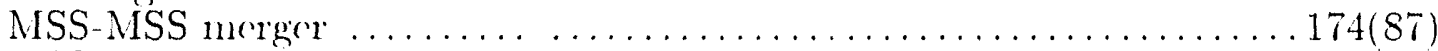

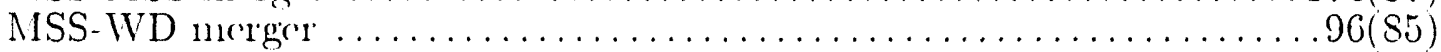

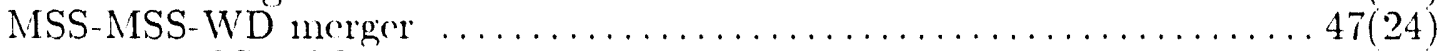

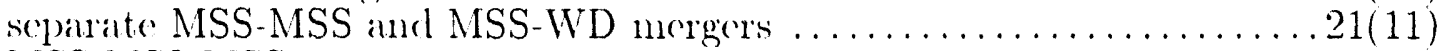

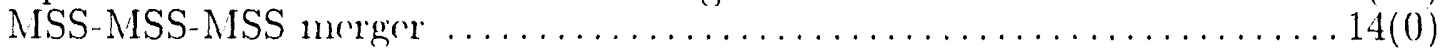

(. (MSS+MSS) (MSS+NS) C'ollisions

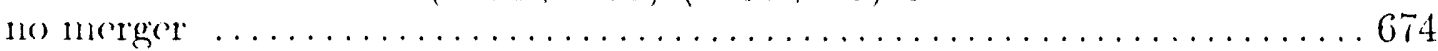

MSS-MSS merger ........................................ 165(49)

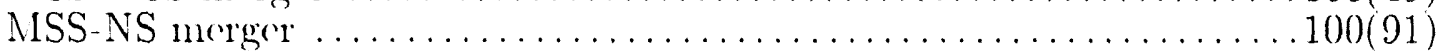

MSS-MSS-NS merger . . . . . . . . . . . . . . . . . . . . . . . . 30(15)

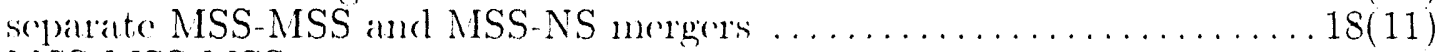

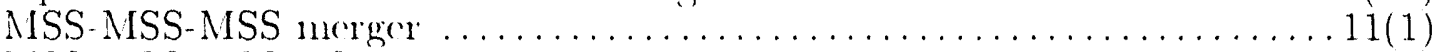

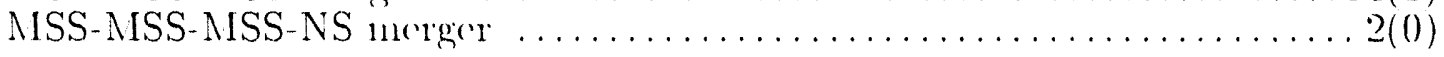

D. (MSS+WD) (MSS + WD) C'ollisions

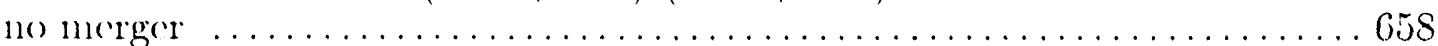

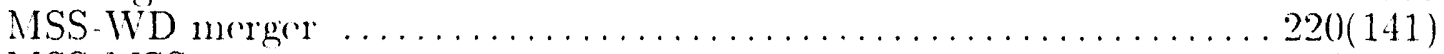

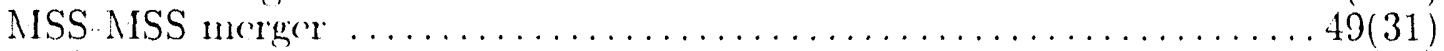

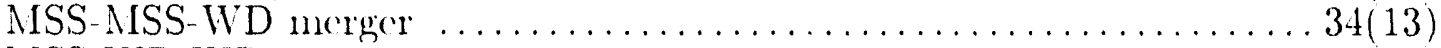

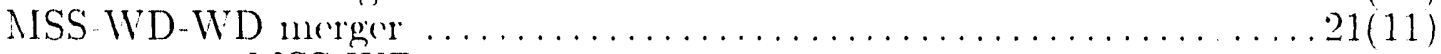

two separate MSS-WWD mergers ...............................

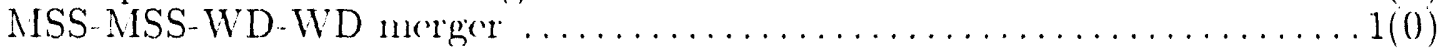


E. (MSS +WD) (MSS + NS) Collisions

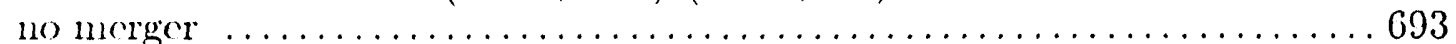

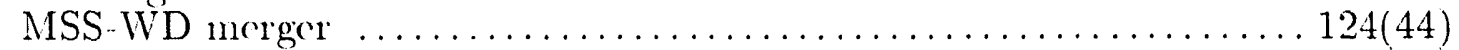

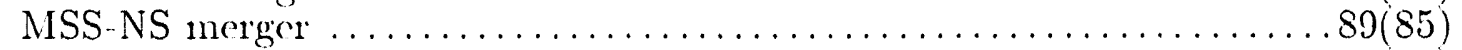

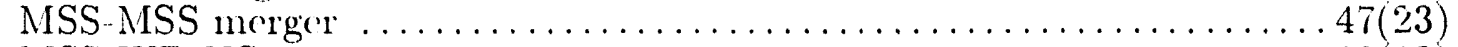

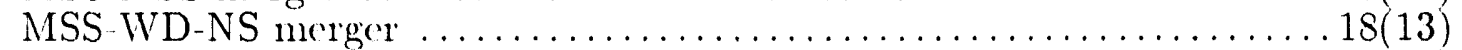

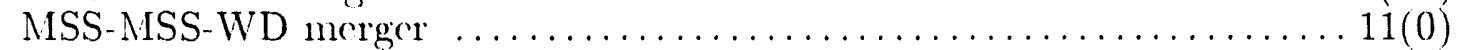

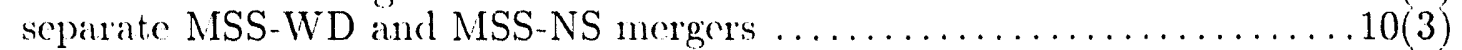

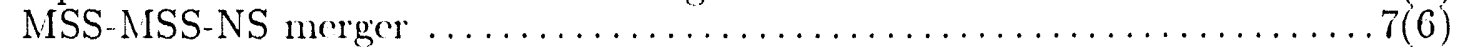

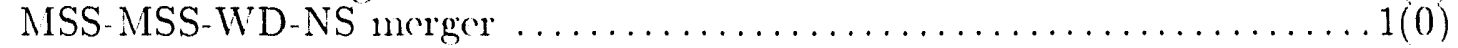

F. $($ MSS + NS $) \cdots($ MSS + NS $)$ Collisions

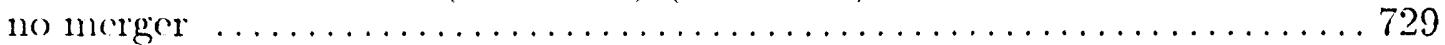

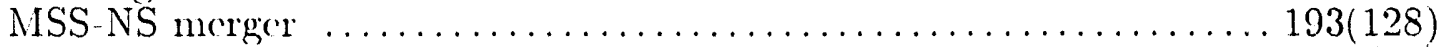

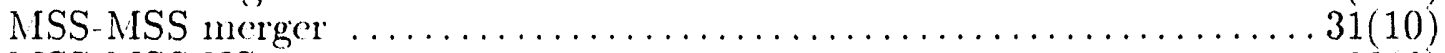

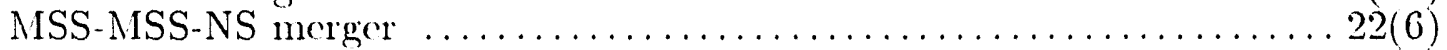

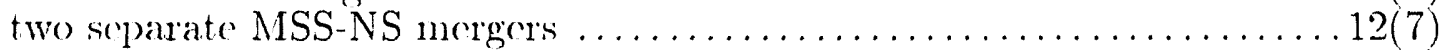

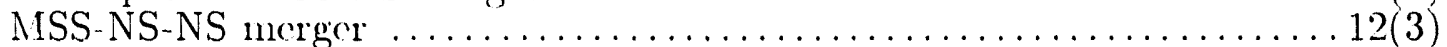

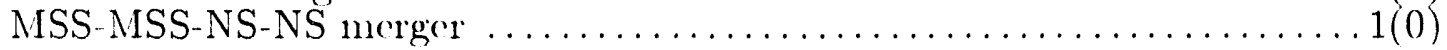

\section{MERGED STARS IN BINARIES}

Most of the morged stars have binary companions, and a small fraction of them are in triple systems. The binaries tend to have periods that are comparable with or longer than the binaries that originally collicled, and the orbits tend to be quite eceentrie. These are the same trends as found for the binary properties of blue stragglers produced via physical stellar collisions during strong binary-binary interactions (Leonard \& Fahlman 1991).

\section{WORK IN PRGCRESS}

We have just begun this project, which is the binary-binary analog of the binary-single study of Davies, Benz \&: Hills (1993). To provide better statistics, we will consider $10^{4}$ runs per kind of collision instead of only $10^{3}$. Point-particle (i.c., zero-radius) experiments corresponding to the cases presented in this paper will be carried ont for comparison. We will also carry ont hydrodynamical simulations of the most interesting merger cases. Merger rates in real globullar clusters will bo estinated. Cross sections for non-merger outcomes (e.g., (xchanges, triple formation, etc...) will also be calculated.

\section{ACKNOWLEDGEMENTS}

This work was supported by the United States Department of Energy, and through an R. C. Tolman Followship awarded to MBD at Caltech.

\section{REFERENCES}

Alexander, M. E. 1986, Jommal of Computational Physies, 64, 195

Davies, M. B., Benz, W., \& Hills, J. G. 1993, ApJ, 411, 285

Leonard, P. J. T., SE Fahlman, G. G. 1991, A.J, 102, 994 

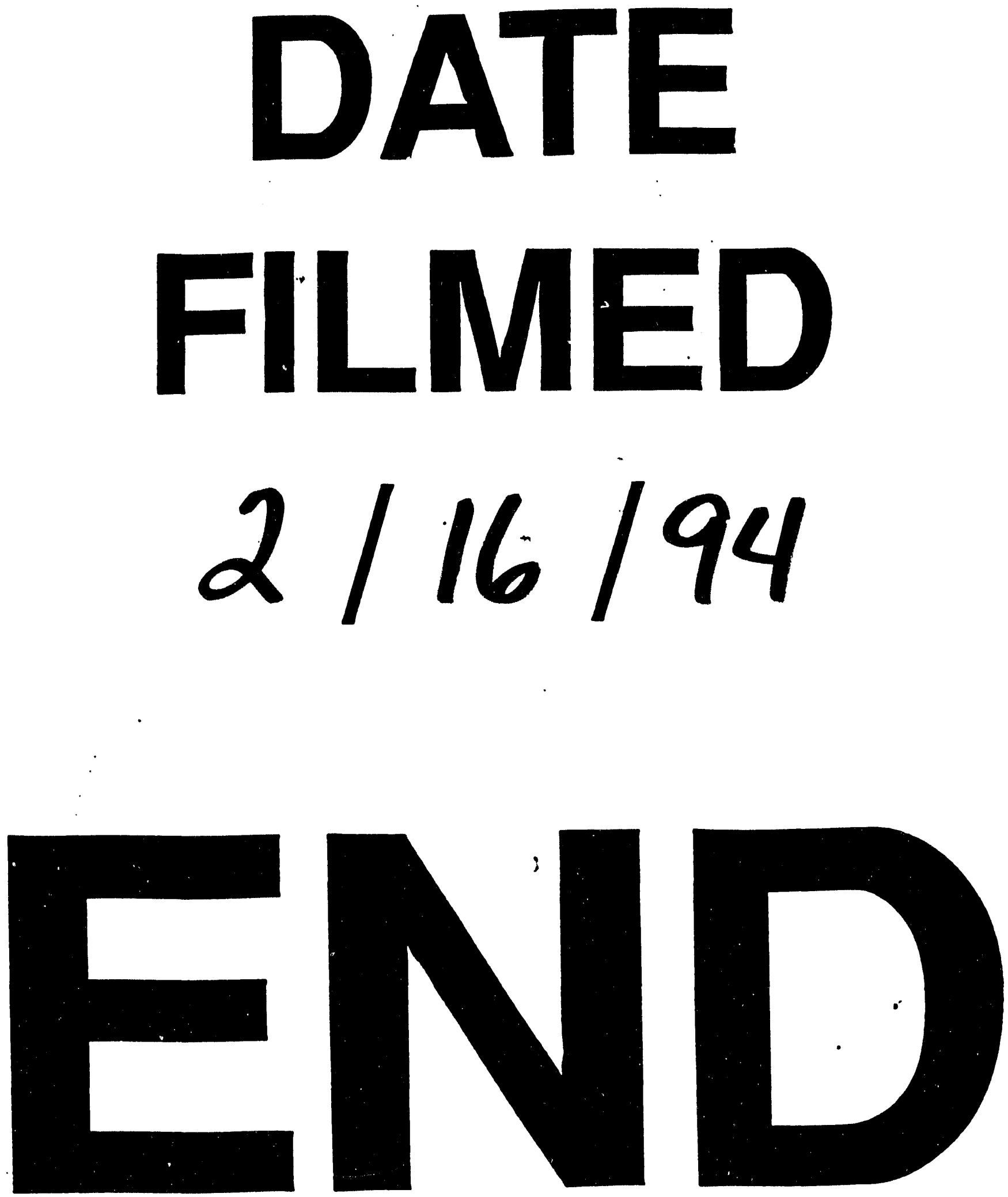
